\title{
Orographic Effects on Extreme Rainfall at Different Durations: A Case Study in Campania Region (Southern Italy)
}

\author{
Pierluigi Furcolo, Anna Pelosi \\ Department of Civil Engineering, University of Salerno, Fisciano (SA), Italy \\ Email: p.furcolo@unisa.it, apelosi@unisa.it
}

How to cite this paper: Furcolo, P., \& Pelosi, A. (2018). Orographic Effects on Extreme Rainfall at Different Durations: A Case Study in Campania Region (Southern Italy). Journal of Geoscience and Environment Protection, 6, 77-88.

https://doi.org/10.4236/gep.2018.611006

Received: September 28, 2018

Accepted: November 18, 2018

Published: November 21, 2018

Copyright $\odot 2018$ by authors and Scientific Research Publishing Inc. This work is licensed under the Creative Commons Attribution International License (CC BY 4.0).

http://creativecommons.org/licenses/by/4.0/

\begin{abstract}
Long-term probabilistic prediction of extreme rainfall at the regional scale is a significant tool in the mitigation of hydro-geological disasters: it actually provides the starting point in the design of strategic hydraulic infrastructures and emergency plans. A crucial task of regional estimation of extreme rainfall is how to include the complex effects of orographic barriers in a mathematical model for Intensity-Duration-Frequency (IDF) curves. Here, an analysis of how orography can affect extreme rainfall at different durations is presented for three orographic systems that are very relevant for hydrological risk assessment in the Campania Region in Southern Italy. Then, we introduce a power law model to link the amplification factor to the duration, thus allowing a simple and effective enhancement of the IDF model in mountainous areas.
\end{abstract}

\section{Keywords}

Orography, Extreme Rainfall, Regional Models, Orographic Amplification, IDF Curves

\section{Introduction}

The strong interaction between topography and atmospheric processes has been observed and studied for a long time. A major aspect of this interaction regards the complex influence on the precipitation patterns (Roe, 2005), which mainly leads to a significant increase of the precipitation amount in mountainous areas in addition to an enhanced spatial variability of the precipitation fields (Prudhomme \& Reed, 1999). An effective modeling of how orography influences both total and extreme rainfall can drastically improve the design criteria of hydraulic 
structures, such as flood protection systems.

In this paper, the research interest is focused on long-term probabilistic predictions of extreme rainfall at the regional scale. Hence, the signature of the orography should be properly included in the spatial model of some statistical parameters that characterize the probability distribution of the annual rainfall maxima (Prudhomme \& Reed, 1999; Allamano, Claps, Laio, \& Thea, 2009; Furcolo, Pelosi, \& Rossi, 2016; Pelosi \& Furcolo, 2015). Higher order statistical parameters are often considered either constant or smoothly varying over relatively large areas due to the sampling errors that usually mask the "true" (if any) spatial variability. Lower order statistics, such as mean, instead, require a more accurate regional model, that clearly has to take account of the orographic effects (Furcolo, Pelosi, \& Rossi, 2016). In addition to the complexity of the phenomenon itself, the multitude of meteorological events with very different features (De Luca, Furcolo, Rossi, Villani, \& Vitolo, 2010), which affects the annual rainfall maxima, makes the task very challenging.

An additional issue is the general lack of data useful for a correct identification of orographic effects over extreme rainfall. Rain gauge networks usually are unevenly spaced, with scarcity of rain gauges in mountain areas, right where a higher density of the network would be needed in order to observe the enhanced spatial variability of the precipitation field. This circumstance makes the rainfall measurements often unsuitable for the application of typical regionalization procedures, as linear regression models or geostatistical approaches (Prudhomme \& Reed, 1999; Furcolo, Pelosi, \& Rossi, 2016; Pelosi \& Furcolo, 2015).

To deal with the orographic effects on extreme rainfall estimation, the traditional regionalization approach uses local descriptors of topography, namely, in the simplest case, the elevation (Rossi \& Villani, 1994; Burlando \& Rosso, 1996). This approach tends to oversimplify the complex effects of orography on extreme rainfall, resulting in regression errors that often are spatially correlated.

More recent approaches couple a regression model with spatial interpolation techniques. The aim is to capture the complex interactions of rainfall with orography by describing the general dependence of rainfall on site-based synthetic descriptors of topography and meteorology. In scientific literature, we found that these descriptors vary in number and have different degrees of complexity, e.g. elevation, slope, average distance from the see, exposition, atmospheric moisture and so on (Prudhomme \& Reed, 1999; Allamano, Claps, Laio, \& Thea, 2009; Castro, Gironás, \& Fernández, 2014; Masson \& Frei, 2014; Avanzi, \& De Michele, 2015). The latter approaches have led to significant advances in regional modelling accuracy, at the cost of a moderate increase in the number of model parameters.

However, another way to improve regional models is to approach the description of a site's orography in a completely new way, such as the one proposed by recent studies in Italy (Pelosi \& Furcolo, 2015; Furcolo, Pelosi, \& Rossi, 2016). This novel approach employs an innovative geographic information system-based, 
objective geomorphological procedure (Cuomo, Guida, \& Palmieri, 2011) for the identification and characterization of orographic barriers from a digital elevation model (DEM) of topography.

In this study, following the works by Pelosi \& Furcolo (2015) and Furcolo, Pelosi, \& Rossi (2016) we propose a novel method for implementing the orographic effects on the regional estimation of the Intensity-Duration-Frequency (IDF) curves in Campania region (Southern Italy). Due to the aforementioned scarcity of rain gauges in orographic areas, the analyses are focused only on some orographic barriers that have a satisfactory number of rain gauges. The presence of a high number of rain gauges in these barriers corresponds to the need of improving risk mitigation measures that have been implemented after some hydro-geological disasters that stroke those areas in the past. We use the availability of these rainfall measurements to extend our knowledge about orographic effects on extreme rainfall and to proceed toward the formulation of more accurate regional models for annual rainfall maxima estimation.

In Section 2, the study area and rainfall data are presented in addition to the current state of the art of the regional model for extreme rainfall assessment and the new methods proposed. In Section 3, the results of this study are introduced and discussed.

\section{Materials and Methods}

\subsection{Study Area and Rainfall Database}

The study area is the Campania region, located in Southern Italy between the Mediterranean Sea and the Apennine Mountains. Figure 1 shows a Digital Elevation Model (DEM) of the area, which is characterized by a very complex topography with an irregular orography. The DEM has been released by ISPRA (Istituto Superiore per la Protezione e la Ricerca Ambientale-Italian Institute for the Environmental Protection and Research) and it can be downloaded from the website http://www.sinanet.isprambiente.it.

Cuomo, Guida, \& Palmieri (2011) systematize the orography of the region through a Geographical Information System (GIS)-based geomorphological procedure. This procedure automatically identifies the orographic barriers and classifies them in a way similar to the well-known drainage network ordering system, according to some topographic indices, such as key contour, key saddle, summit point, prominence, and others. Figure 1 shows with solid red lines the perimeters of the $3^{\text {rd }}$ order (systems) and $4^{\text {th }}$ order (groups) of orography, which is the scale comparable to the main meteorological processes that give rise to extreme rainfall in the region.

The rainfall database used in the study is made up of time series of rainfall annual maxima at different durations (1, 3, 6, 12 and 24 hours). The database put together the older rainfall measurements collected by the raingauge network of the SIMN (Servizio Idrografico e Mareografico Nazionale-Italian Hydrographic and Mareographic Service), from year 1920 to 2000, and at the newer 


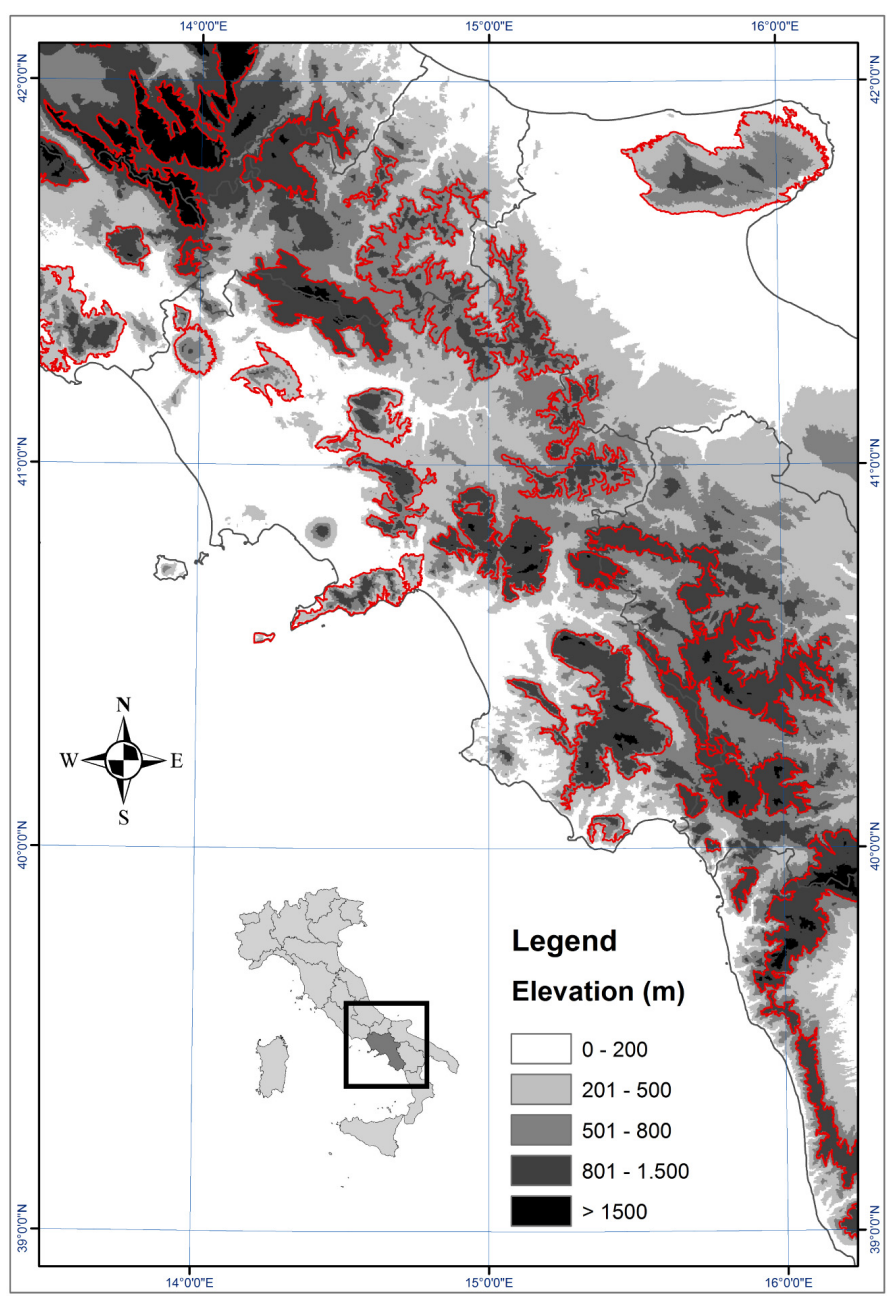

Figure 1. Digital Elevation Model (DEM) of the study area, released by ISPRA (Istituto Superiore per la Protezione e la Ricerca Ambientale-Italian Institute for the Environmental Protection and Research). The solid red lines indicate the perimeters of the orographic barriers ( $3^{\text {rd }}$ and $4^{\text {th }}$ orders), as identified by Cuomo, Guida, \& Palmieri (2011).

real-time raingauge network managed by the local Operational Center (Centro funzionale multirischi di Protezione Civile della Regione Campania), from year 2001 to 2015.

Figure 2 shows the two networks on the map along with the orographic barriers. It should be noted that the current rain gauge network consists of the historical stations (some of them are still active and now managed by the local Operational Center) and 164 new real-time stations installed by the local Operational Center, partly replacing the historical stations, also with displacements of the installation site of the order of $1 \mathrm{~km}$.

Overall, the rain gauge monitoring network includes a total of 270 stations in the regional area. After year 2001, however, only the data recorded by the newest network are currently available, while data measured from about 50 traditional rain gauges of the former SIMN network are available until year 2000.

Moreover, it should be noted the particular attention that was paid to the design 


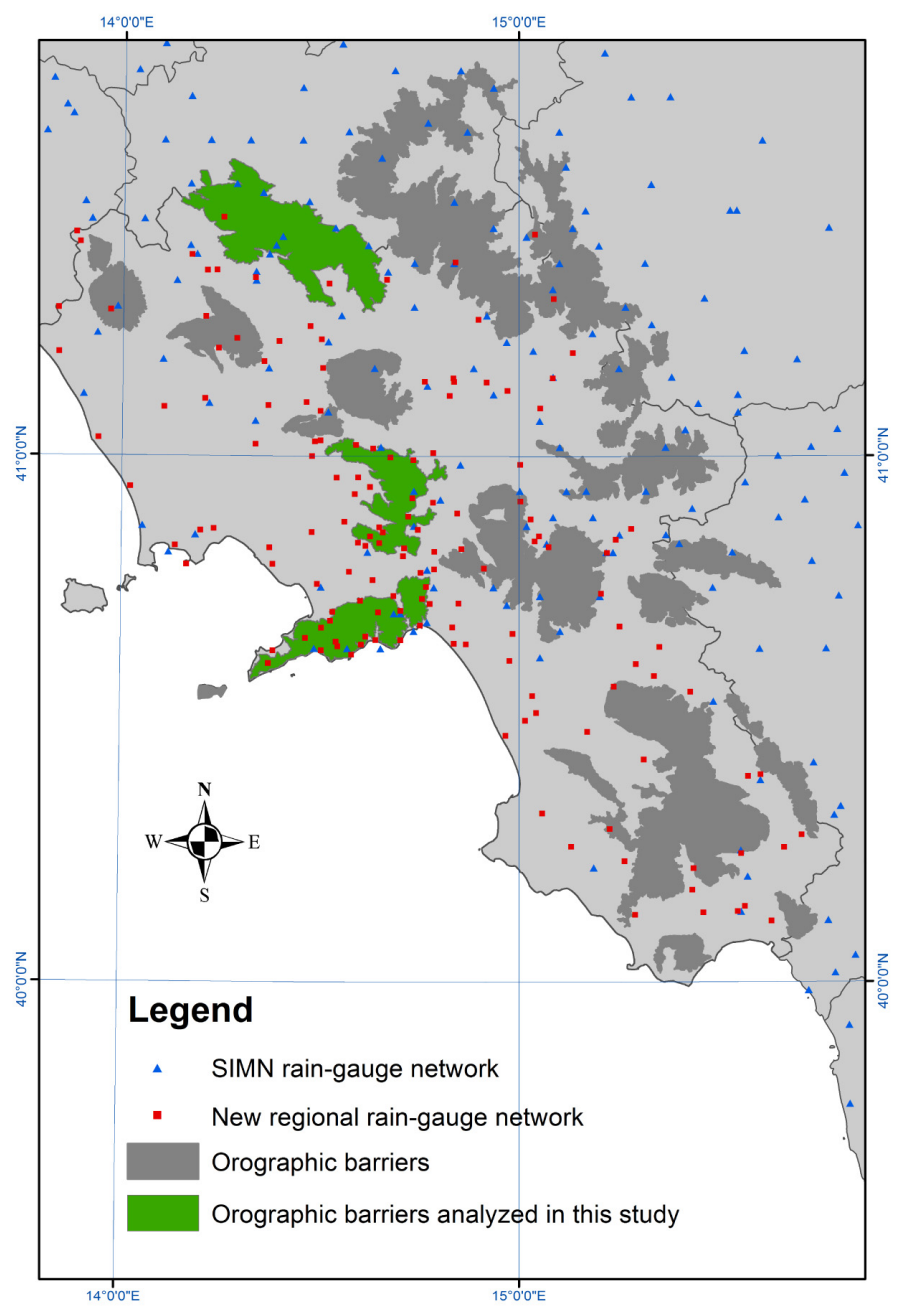

Figure 2. Map of the study area showing the SIMN rain-gauge network (blue triangles) and the new regional rain-gauge network (red squares) with all the orographic barriers (dark grey shapes), as identified by Cuomo, Guida, \& Palmieri (2011) and the orograhic barriers that are analyzed in this study (green shapes).

of the new network, which has increased on average the density of rain gauges in orographic areas, partly filling the unevenness of the SIMN rain-gauge network. In particular, many monitoring stations have been installed in the orographic areas affected by hydrogeological instability (Chirico, Claps, Rossi, \& Villani, 2000; Cascini, Cuomo, \& Della Sala, 2011; Bovolin, 2012; Ciervo, Papa, Medina, \& Bateman, 2015). Among these areas, we may find 1) the cliffs of the Sorrentine Peninsula, in the Lattari Mountains, located very close to the sea (Amalfi and Sorrentine Coasts) and 2) the Sarno and Avella-Partenio Mountains. For the case of Lattari Mountains the number of rain gauges was increased from 4 to 15, for the second from 2 to 9 . In the following, all the analyses will refer to the aforementioned barriers both for the large number of stations and for the interest that these areas have in defense against hydrogeological risks. Furthermore, a third barrier is considered, i.e. the Matese Massif, for which the number of measuring stations is equal to 5 . 
The chosen orographic barriers are representative of three different typologies of interaction with the dominant direction of the wet air masses that are responsible of extreme rainfall. In the studied region, the rainfall is largely generated by wet air masses that come predominantly from the Tyrrhenian Sea (i.e. southwest-northeast direction). The investigation of these three barriers is particularly interesting because they mainly differ each other for both the exposition to wet air masses (Pelosi \& Furcolo, 2015) and distance from the sea. The other barriers, showed in grey in Figure 2, are not considered in the analysis because they have a small number (less than 5) of monitoring stations. The barrier placed to the North-West of the Campania region deserves a separate mention: although having 17 measuring stations, it has not been included in this study. It is a barrier with an irregular shape, with modest prominence and in relative backward position with respect to the Mediterranean Sea: for these reasons, as pointed out in Pelosi \& Furcolo (2015), it already showed a negligible amplification effect at a daily scale. Considering the main purpose of this work, which consists of the analysis of the relationship between the amplification due to the orographic barriers and the duration of extreme rainfall, this orographic barrier was considered not significant.

\subsection{Regional Estimation of Extreme Rainfall: State of the Art and Methods}

The current regional model for extreme rainfall estimation in Campania Region comes from the VAPI (VAlutazione delle PIene, Flood Estimation) national project (Rossi \& Villani, 1994). Since its first formulation, it has been only slightly updated, mostly as a consequence of the availability of new data. The core of the model has remained unchanged: it is based on the TCEV parent distribution, with three hierarchical levels or regional estimation of the parameters (Fiorentino, Gabriele, Rossi, \& Versace, 1987). The shape and scale parameters are assumed constant with the duration, thus allowing to de-couple the dependence on the return period from the dependence on the duration as follows:

$$
h_{d, T}=\bar{h}_{d} K_{T} .
$$

where $d$ stands for the duration of the extreme event and $\bar{h}_{d}$ is the mean of the rainfall annual maxima at a given duration and for a specific site. $K_{T}$ represents the growth curve and it is equal to a dimensionless quantile, with return period equal to $T$, and depends on the shape and scale parameters of the maxima distribution.

The first two levels are devoted to shape and scale parameters estimation. The point estimators of such parameters are subjected to large sampling errors that make spatial variability statistically indistinguishable from sampling variability: as a result, the whole region is assumed homogeneous, with constant values of these parameters. This leads to a unique formulation of the growth curve $K_{T}$ for the whole region.

The third level of the regional procedure deals with the estimation of the 
mean of the annual maxima at different durations, $\bar{h}_{d}$. The mean of the annual maxima is the main part of the regional IDF model. In the current VAPI formulation, for durations above 1 hour, the IDF model can be well approximated bya power law:

$$
\bar{h}_{d}=a \cdot d^{n}
$$

where $a$ and $n$ vary along the region as specified by Rossi \& Villani (1994). In particular, the Campania region is divided into 6 sub-regions; in each sub-region, a simple dependence of the exponent of the power law with the elevation is introduced to take account of the orographic effect.

Furcolo, Pelosi, \& Rossi (2016) have found that some orographic objects, objectively identified through a geomorphological procedure (Cuomo, Guida, \& Palmieri, 2011), can be used for improving the regional model at the third level, by coupling a stationary random field model with a deterministic amplification factor that accounts for the presence of orographic barriers. Pelosi \& Furcolo (2015) have shown how this approach can be useful to improve the estimation of extreme rainfall at a daily time scale. In this study, we present some significant preliminary analyses to employ the approach shown in Furcolo, Pelosi, \& Rossi (2016) and Pelosi \& Furcolo (2015) for improving the estimation of rainfall maxima at different durations.

In orographic areas, the mean of the annual maxima could be written as follows:

$$
\bar{h}_{d}=\bar{h}_{d}^{\prime} \cdot A F(d)
$$

where $\overline{h_{d}^{\prime}}$ is a "base process" in space, which represents the value of $\bar{h}_{d}$ in absence of any drift produced by orographic barriers. As shown in Furcolo, Pelosi, \& Rossi (2016), spatial variability of $\overline{h_{d}^{\prime}}$ can be well described through a stationary random field model. Dependence of $\bar{h}_{d}^{\prime}$ on duration is still well described by a power law as in Equation (2), with different parameters $a^{\prime}$ (instead of a) and $n^{\prime}$ (instead of $n$ ), to be estimated by using only rain data recorded in the valleys.

As presented in the Results and Discussion Section, for each measurement site within an orographic barrier, raw $A F$ measurements are computed, according to Equation (3), as follows. The sampling means of the annual maxima of rainfall depths at different durations are divided by the corresponding values of $\bar{h}_{d}^{\prime}$, estimated through the Ordinary Kriging method applied to the rain gauges in the valleys. The data show that the dependence of amplification factor $A F$ on the duration can be expressed through a power law:

$$
A F(d)=a^{\prime \prime} \cdot d^{n^{\prime \prime}}
$$

The parameters $a^{\prime \prime}$ and $n^{\prime \prime}$ are estimated by pooling together raw $A F$ measurements of the rain gauges belonging to the same orographic object.

By combining Equation (2) written for $\bar{h}_{d}^{\prime}$ and Equation (3) \& Equation (4), it could be written:

$$
\bar{h}_{d}=a^{\prime} a^{\prime \prime} \cdot d^{\left(n^{\prime}+n^{\prime \prime}\right)}
$$


Equation (5) represents the updated regional model to estimate the mean of the rainfall annual maxima at different durations in orographic areas. It is evident that the model in Equation (5) is a power law just as Equation (2), but its parameters, in orographic areas, combine the regionalized parameters $a^{\prime}$ and $n^{\prime}$ with the parameters of the deterministic orographic drift, $a^{\prime \prime}$ and $n^{\prime \prime}$.

\section{Results and Discussion}

In this Section, we present and discuss the results of this study, in order to achieve an improvement of the actual regional model used to estimate the mean of the rainfall annual maxima at different durations in orographic areas.

Figure 3 shows, in the left panel, the barriers of interest for the study and, in the right panel, the variation of the amplification factor with the rainfall duration on a bi-logarithmic plot (colored dots).

Power law models give a good fit of the data. The fitted models are represented on the right panel of the same figure as solid lines (since the plot has bi-logarithmic axes) along with the prediction intervals, whose upper and lower bounds are set at $\pm \sigma$ (i.e. the estimated standard deviation of differences between the values obtained from the fitted regression lines and the empirical values).

On the figure, it is also indicated the coefficient of determination $\mathrm{R}^{2}$ for each model: the values of $\mathrm{R}^{2}$ range from 0.74 to 0.97 . The amplification factor assumes values ranging from 1.11 at rainfall duration of 1 hour to 1.16 at 24 hours, in the case of Barrier n. 1. For the Barrier n. 2, the amplification factor values range from 1.13 at rainfall duration of 1 hour to 1.31 at 24 hours. On average, in the orographic areas of the Campania region the amplification of the extremes due to orographic effects is of the order of $25 \%$.

The Sarno and Avella-Partenio barrier (Barrier n. 2) is the one that shows the clearest dependence of the orographic amplification with duration, as well as the highest average amplification factor among all the barriers considered. This fact confirms the idea that the amplification effects have been the cause of some disastrous events that hit these areas in 1998 (Chirico, Claps, Rossi, \& Villani, 2000; Cascini, Cuomo, \& Della Sala, 2011). The particular exposition of this barrier and, similarly, of the barrier of the Matese Massif, can justify such a result. The two barriers are indeed perpendicular to the dominant direction of the masses of humid air (South-East) and, since the Barrier n. 2 is closer to the sea, it shows a higher amplification. For the barrier of the Matese Massif (Barrier n. 3) the amplification effect seems to mainly relate to extreme events whose duration is longer than 6 hours and for which the amplifying effect is constant, instead. Vice versa, the layout of the Lattari Mountains' barrier, almost parallel to the south-east direction, is such as to justify a lower amplification factor since we are considering the average of the extremes. Further investigations are certainly necessary in order to define a complete model for the whole region, by also incorporating the dependence of the amplification factor on the duration as well as on 


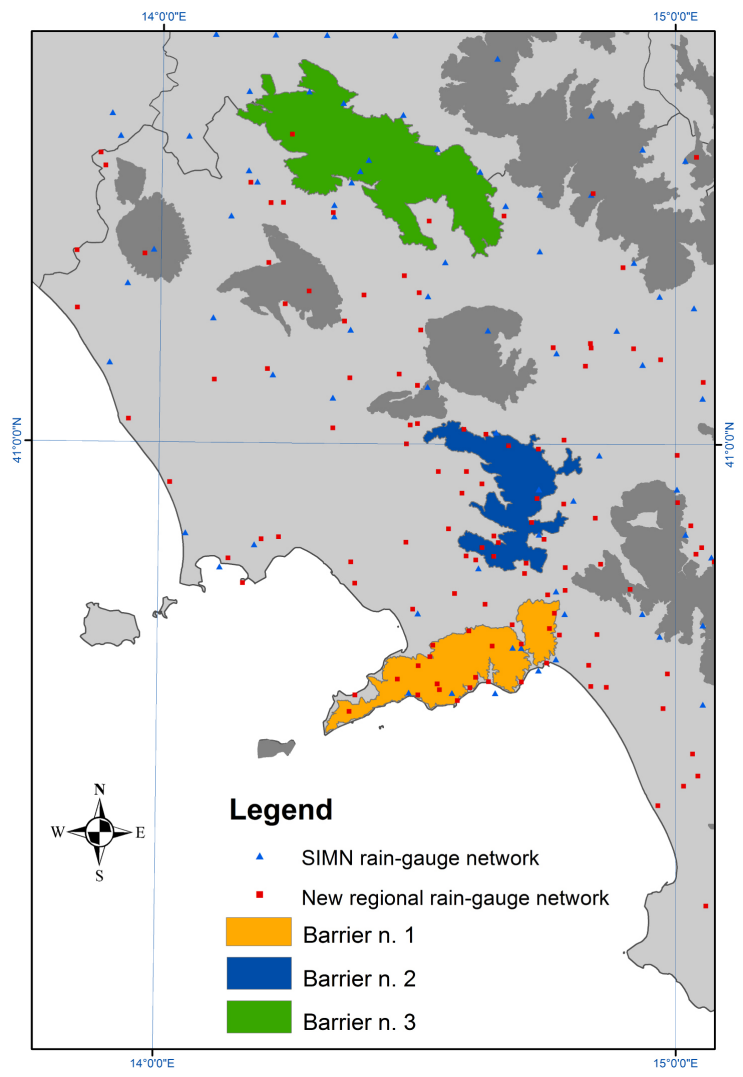

(a)

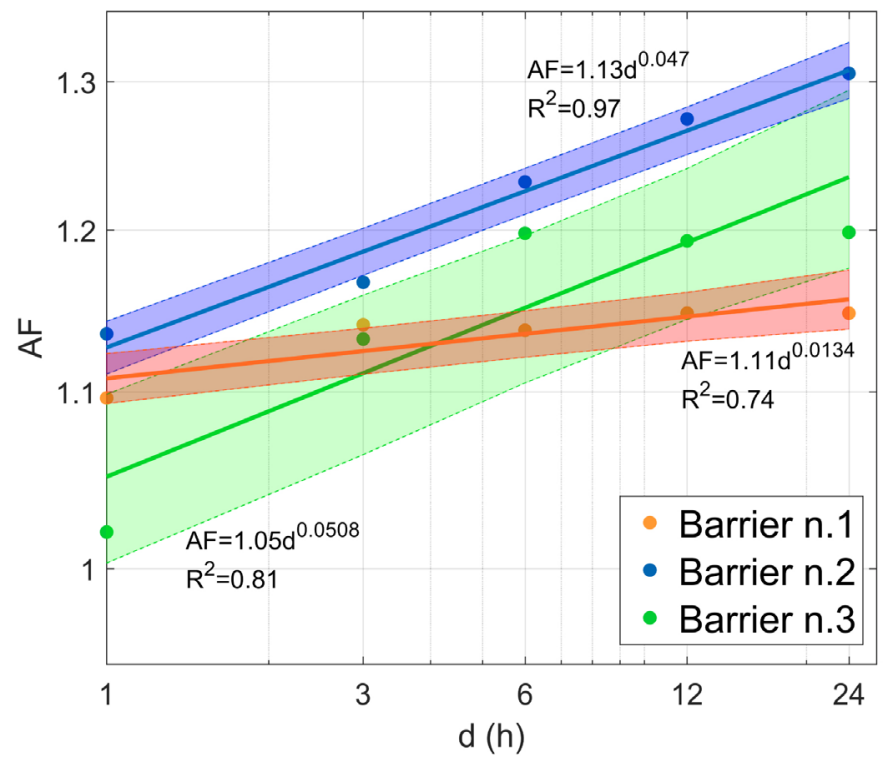

(b)

Figure 3. (a) Orographic barriers of interest, chosen from Cuomo, Guida, \& Palmieri (2011); (b) Computed amplification factorsat different rainfall durations (dots) and fitted power law model (bold solid lines) with prediction itervals (dashed lines).

the topographic features of the orographic barriers, such as exposition, prominence and slope as suggested by Pelosi \& Furcolo (2015) for daily extremes. 


\section{Concluding Remarks}

The amplification of intense rainfall in orographic areas is determinant in triggering several natural disasters (landslides, debris flows, flash floods...). An accurate estimation of such amplification is therefore crucial for the correct design of risk mitigation systems. Whilst meteorological models can often give an accurate evaluation of the influence of orography over rainfall for a given event, introducing orographic effects in regional models of extreme rainfall is a complex and challenging task. The problem is even more complex when the interest is in the IDF curves estimation, since hourly data are historically less available than daily data.

Given the availability of a good amount of data, related to the particular interest for hydrological risk assessment, over three orographic barriers in Campania Region, it has been possible to investigate how orographic amplification acts on extreme rainfall at different durations. It has been found that a power law model can be fitted to the amplification factor, thus allowing for its simple and effective incorporation into a regional model for IDF curves. The results show that extreme rainfall is amplified by orography, and this amplification is enhanced at longer durations. This observation is consistent with the fact that longer rainfall events are more frequently generated by frontal systems, for which the orographic effect is usually stronger. The proposed model is able to properly describe such variability and represents a big step forward compared to the current regional model of IDF curves.

The results of this case study already show how the proposed approach can improve the current regional model for extreme rainfall in the Campania region. As the rain-gauge network becomes denser, and the availability of data, especially on mountainous areas, increases, this approach can be extended to the whole region in order to completely revise the third level of the VAPI regional model. Furthermore, since our approach is based on the automatic identification of orographic barriers, it can be easily exported to other regions, in Italy as well as in the Mediterranean basin.

\section{Acknowledgements}

This work has been funded by University of Salerno through the FARB no. 300393FRB17FURCOLO ("Modelli Idrologici avanzati per la Valutazione del Rischio”-Advanced Hydrological Models for Risk Assessment).

\section{Conflicts of Interest}

The authors declare no conflicts of interest regarding the publication of this paper.

\section{References}

Allamano, P., Claps, P., Laio, F., \& Thea, C. (2009). A Data-Based Assessment of the Dependence of Short Duration Precipitation on Elevation. Physics and Chemistry of the 
Earth, 34, 635-641. https://doi.org/10.1016/j.pce.2009.01.001

Avanzi, F., \& De Michele, C. (2015). Orographic Signature on Extreme Precipitation of Short Durations. Journal of Hydrometeorology, 6, 278-294. https://doi.org/10.1175/JHM-D-14-0063.1

Bovolin, V. (2012). Studio idraulico dell'evento alluvionale avvenuto ad Atrani (SA) il 9 settembre 2010. Parte I: ricostruzione dell'evento. Fisciano: Cooperativa Universitaria Editrice Studi (In Italian).

Burlando, P., \& Rosso, R. (1996). Scaling and Multiscaling Models of Depth-DurationFrequency Curves for Storm Precipitation. Journal of Hydrology, 187, 45-64. https://doi.org/10.1016/S0022-1694(96)03086-7

Cascini, L., Cuomo, S., \& Della Sala, M. (2011). Spatial and Temporal Occurrence of Rainfall-Induced Shallow Landslides of Flow Type: A Case of Sarno-Quindici, Italy. Geomorphology, 126, 148-158. https://doi.org/10.1016/j.geomorph.2010.10.038

Castro, L. M., Gironás, J., \& Fernández, B. (2014). Spatial Estimation of Daily Precipitation in Regions with Complex Relief and Scarce Data Using Terrain Orientation. Journal of Hydrology, 517, 481-492. https://doi.org/10.1016/j.jhydrol.2014.05.064

Chirico, G. B., Claps, P., Rossi, F., \& Villani P. (2000). Hydrologic Conditions Leading to Debris-Flow Initiation in the Campanian Volcanoclastic Soil. In P. Claps, \& F. Siccardi (Eds.), Mediterranean Storms: Proceedings EGS Plinius Conference (pp. 473-484). Cosenza: Editoriale Bios.

Ciervo, F., Papa, M. N., Medina, V., \& Bateman, A. (2015). Simulation of Flash Floods in Ungauged Basins Using Post-Event Surveys and Numerical Modelling. Journal of Flood Risk Management, 8, 343-355. https://doi.org/10.1111/jfr3.12103

Cuomo, A., Guida, D., \& Palmieri, V. (2011). Digital Orographic Map of Peninsular and Insular Italy. Journal of Maps, 7, 447-463. https://doi.org/10.4113/jom.2011.1209

De Luca, C., Furcolo, P., Rossi, F., Villani, P., \& Vitolo, C. (2010). Extreme Rainfall in the Mediterranean. Proceedings of the International Workshop: Advances in Statistical Hydrology, 1-9.

Fiorentino, M., Gabriele, S., Rossi, F., \& Versace, P. (1987). Hierarchical Approach for Regional Flood Frequency Analysis. In V. Singh (Ed.), Regional Flood Frequency Analysis (pp. 35-49). Dordrecht: Reidel. https://doi.org/10.1007/978-94-009-3959-2_4

Furcolo, P., Pelosi, A., \& Rossi, F. (2016). Statistical Identification of Orographic Effects in the Regional Analysis of Extreme Rainfall. Hydrological Processes, 30, 1342-1353. https://doi.org/10.1002/hyp.10719

Masson, D., \& Frei, C. (2014). Spatial Analysis of Precipitation in a High-Mountain Region: Exploring Methods with Multi-Scale Topographic Predictors and Circulation Types. Hydrology and Earth System Science, 18, 4543-4563. https://doi.org/10.5194/hess-18-4543-2014

Pelosi, A., \& Furcolo, P. (2015). An Amplification Model for the Regional Estimation of Extreme Rainfall within Orographic Areas in Campania Region (Italy). Water, 7, 6877-6891. https://doi.org/10.3390/w7126664

Prudhomme, C., \& Reed, D. (1999). Mapping Extreme Rainfall in a Mountainous Region Using Geostatistical Techniques: A Case Study in Scotland. International Journal of Climatology, 19, 1337-1356.

https://doi.org/10.1002/(SICI)1097-0088(199910)19:12<1337::AID-JOC421>3.0.CO;2-G

Roe, G. H. (2005). Orographic Precipitation. Annual Review of Earth and Planetary Sciences, 33, 645-671. https://doi.org/10.1146/annurev.earth.33.092203.122541

Rossi, F., \& Villani, P. (1994). A Project for Regional Analysis of Flood in Italy. In G. Ros- 
si, N. Harmancioglu, \& V. Harmancioglu (Eds.), Coping with Floods: Proceedings of the NATO Advanced Study Institute (pp. 227-251). Berlin: Springer-Science + Business Media, B.V. https://doi.org/10.1007/978-94-011-1098-3_11 